\begin{tabular}{llllllll}
\hline & $R$ & $\mathrm{R}$ & $\mathrm{V}$ & $\mathrm{I}$ & $\mathrm{E}$ & $\mathrm{W}$
\end{tabular}

\title{
Natriuretic peptides and cardiovascular damage in the metabolic syndrome: molecular mechanisms and clinical implications
}

\author{
Carmine SAVOIA* $†$, Massimo VOLPE* $\ddagger$, Alessandro ALONZO*, Chiara ROSSI* and \\ Speranza RUBATTU* $\ddagger$ \\ *Cardiology Unit, Second Faculty of Medicine, Sant'Andrea Hospital, Sapienza University of Rome, Rome, Italy, †Research \\ Center, Fatebenefratelli San Pietro Hospital, Rome, Italy, and ‡IRCCS Neuromed, Polo Molisano University of Rome La \\ Sapienza, Pozzilli (Is), Italy
}

\section{A}

\begin{abstract}
Natriuretic peptides are endogenous antagonists of vasoconstrictor and salt- and waterretaining systems in the body's defence against blood pressure elevation and plasma volume expansion, through direct vasodilator, diuretic and natriuretic properties. In addition, natriuretic peptides may play a role in the modulation of the molecular mechanisms involved in metabolic regulation and cardiovascular remodelling. The metabolic syndrome is characterized by visceral obesity, hyperlipidaemia, vascular inflammation and hypertension, which are linked by peripheral insulin resistance. Increased visceral adiposity may contribute to the reduction in the circulating levels of natriuretic peptides. The dysregulation of neurohormonal systems, including the renin-angiotensin and the natriuretic peptide systems, may in turn contribute to the development of insulin resistance in dysmetabolic patients. In obese subjects with the metabolic syndrome, reduced levels of natriuretic peptides may be involved in the development of hypertension, vascular inflammation and cardiovascular remodelling, and this may predispose to the development of cardiovascular disease. The present review summarizes the regulation and function of the natriuretic peptide system in obese patients with the metabolic syndrome and the involvement of altered bioactive levels of natriuretic peptides in the pathophysiology of cardiovascular disease in patients with metabolic abnormalities.
\end{abstract}

\section{INTRODUCTION}

The MS (metabolic syndrome) represents a constellation of several established and emerging risk factors in which insulin resistance may be recognized as a common pathophysiological background [1]. A universal definition of the MS does not exist; however, the two most adopted definitions of the MS are those proposed by the WHO (World Health Organization) [2] and NCEPATP III (National Cholesterol Education Program Adult Treatment Panel III) [3]. The defining criteria are based on levels of waist circumference, serum triacyglycerols (triglycerides), blood HDL (high-density lipoprotein)cholesterol levels, BP (blood pressure) and serum glucose.

Key words: cardiovascular disease, metabolic syndrome, natriuretic peptide, obesity, remodelling, renin-angiotensin system. Abbreviations: ACE, angiotensin-converting enzyme; AngII, angiotensin II; BMI, body mass index; BP, blood pressure; CAD, coronary artery disease; COX-2, cyclo-oxygenase-2; ET, endothelin; HDL, high-density lipoprotein; LDL, low-density lipoprotein; LV, left ventricular; LVH, LV hypertrophy; MAPK, mitogen-activated protein kinase; MS, metabolic syndrome; NEFA, nonesterified fatty acid; NEP, neutral endopeptidase; NP, natriuretic peptide; ANP, atrial NP; BNP, brain NP; CNP, C-type NP; NPR, NP receptor; NT-proBNP, N-terminal pro-BNP; PKG, protein kinase G; RAAS, renin-angiotensin-aldosterone system; ROS, reactive oxygen species; TGF- $\beta$, transforming growth factor- $\beta$; TNF- $\alpha$, tumour necrosis factor- $\alpha$.

Correspondence: Dr Carmine Savoia (email savoiac@yahoo.it). 
It has been largely demonstrated that the MS has a negative impact on cardiovascular prognosis, being associated with the development of overt diabetes, established hypertension, and cardiovascular and cerebrovascular disease, including CAD (coronary artery disease), heart failure and stroke [2,3]. The key components of the MS are abdominal obesity, atherogenic dyslipidaemia, elevated $\mathrm{BP}$, glucose intolerance, and pro-inflammatory and prothrombotic states $[1,4]$. Increased visceral adiposity is becoming a major global health problem in industrialized countries, as well as developing countries, and it is closely associated with the MS, hypertension and increased cardiovascular risk. Increased abdominal adiposity appears to play a relevant role in metabolic (for example, the MS and diabetes mellitus) and cardiovascular (for example, CAD and stroke) complications, even in moderately overweight subjects $[5,6]$. It has been recognized that visceral adipose tissue is not simply a fat depot, being a highly metabolically active organ which may produce several active cytokines (adipokines) that may induce metabolic and pro-inflammatory actions, as well as predisposing to the development of insulin resistance. Insulin resistance is a major pathophysiological link between visceral adiposity and metabolic and cardiovascular complications [1].

The dysregulation of neurohormonal systems, including the RAAS (renin-angiotensin-aldosterone system) and NP (natriuretic peptide) system, may increase visceral fat mass, as well as contribute to the development of insulin resistance in dysmetabolic patients. In normal subjects, NPs may affect the homoeostasis of glucose and lipid metabolism, partly through the reduction in adipogenesis, as well as the increased release and more efficient consumption of NEFAs (non-esterified fatty acids) by peripheral tissues. Furthermore, evidence from experimental and clinical studies have shown that NP levels are not simply markers of cardiovascular pathology; rather they are directly involved in the pathophysiology of cardiovascular diseases, particularly in dysmetabolic patients [7]. Indeed, NPs exert relevant cardioprotective functions, being involved in cardiovascular homoeostasis through the regulation of body fluid and BP by promoting natriuresis, as well as by modulating vascular inflammation and cardiovascular remodelling.

It has been shown that NPs are abnormally regulated in obesity and the MS [8]. In particular, in obese subjects, NP levels are reduced, and this may contribute to the genesis of insulin resistance, and to the pathophysiology of hypertension and its complications in subjects with the MS $[9,10]$. Low levels of NPs may also predispose to pro-inflammatory and profibrotic states in the heart and vasculature, thus contributing to the pathophysiology of cardiovascular remodelling and cardiac hypertrophy. Those conditions frequently occur in patients with the MS and correlate with increased cardiovascular risk. In the present review, we summarize the mechanisms of
NP system dysfunction in patients with the MS, as well as the possible involvement of the altered regulation of NPs in the development of cardiovascular damage in dysmetabolic subjects.

\section{FUNCTION OF NPS AND METABOLIC ALTERATIONS}

The NP family consists of three peptides: ANP (atrial NP), BNP (brain NP) and CNP (C-type NP), which have structural and physiological similarities. Studies in animals and humans have confirmed the importance of these peptides as endogenous antagonists of vasoconstrictor and salt- and water-retaining systems [such as the RAAS, ETs (endothelins) and vasopressin], and in the body's defence against BP elevation and plasma volume expansion, through direct vasodilator, diuretic and natriuretic properties. NPs may also modulate vascular inflammation, cell growth and cardiovascular remodelling [11]. Furthermore, NPs may participate in the modulation of the molecular mechanisms involved in metabolic regulation. In particular, NPs are involved in the homoeostasis of plasma lipids and adipose tissue formation.

NPs bind to high-affinity receptors (NPR-A, NPR$B$ and NPR-C) on the surface of target cells [12]. NPR-A and -B are structurally similar, are linked to the production of cGMP, and mediate many of the cardiovascular and renal effects of NPs. NPR-A binds both ANP and BNP, with the highest affinity being for ANP. On the other hand, CNP appears to be the natural ligand for NPR-B. NPR-C has sequence homology with the other two receptors, but lacks the intracellular catalytic domains of guanylate cyclase. All three NPs bind to this receptor with similar affinity. NPR-C is widely expressed in a variety of tissues, including adipose tissue. Although it has been reported that this receptor induces a G-protein-linked cAMP activation [13] and, thus is involved in the cellular mechanisms of the antigrowth properties of NPs, it is generally accepted that NPR-C plays a major role in the local modulation of the physiological effects of NPs, by modulating the final ANP and BNP binding to NPR-A and by acting as the clearance receptor of NPs [14]. Both ANP and BNP are rapidly removed from the circulation by this receptor [15]. Lungs, liver and kidney, as well as adipose tissue, are important sites for the elimination of endogenous NPs. Circulating NPs are also inactivated by cleavage through NEPs (neutral endopeptidases) within renal tubular and vascular cells.

NPs, through the activation of the biologically active membrane guanylate-cyclase-linked NPR-A, induce a potent lipolytic effect in vitro and in vivo in human adipocytes via a cGMP-dependent mechanism [16] and the activation of hormone-sensitive lipase [17]. This lipolytic effect is independent of the fat cell adrenergic and insulin pathways [18], and is enhanced by hypocaloric 
diets and weight loss [19]. The NP lipolytic pathway is involved in the lipid mobilization observed during physical activity [20], which is recognized as one of the main nonpharmacological approaches to improve insulin resistance and prevent obesity, diabetes and cardiovascular disease. During physiological increases in plasma ANP levels, enhanced lipid mobilization is associated with an increase in lipid utilization by peripheral tissues [17]. It is well established that during exercise NEFA production and consumption is enhanced in the heart and skeletal muscle. During physical activity, the heart derives energy for myocardial contraction mainly by the oxidation of fatty acids in mitochondria [21], whose biogenesis requires cGMP as a key mediator [22]. In this regard, NPs may promote oxidative metabolism in the heart, as well as in the skeletal muscle, by increasing NEFA release and possibly cGMP-dependent mitochondrial activation. Under these conditions, increased NEFA consumption may counterbalance the negative effects associated with the high plasma NEFA levels that are associated with insulin resistance, metabolic cardiovascular complications [1] and mortality [23]. Conversely, decreased NP signalling may promote lipid accumulation in adipose tissue and skeletal muscle, and may reduce the peripheral NEFA utilization. This may contribute to the development of visceral adiposity, which is associated with dyslipidaemia and insulin resistance [24] (Figure 1). Increased visceral fat depots are associated with the release of proinflammatory mediators [such as interleukins and TNF- $\alpha$ (tumour necrosis factor- $\alpha$ )] and with reduced levels of the anti-inflammatory cytokine adiponectin. This can contribute to impaired hepatic lipoprotein metabolism [25], and may lead to the production of the highly atherogenic small-dense LDL (low-density lipoprotein) particles, which are key features of visceral obesity and are closely related with insulin resistance [25]. Moreover, obesity and the MS are associated with decreased HDL levels and the increased production of small-dense HDL particles, which may act as pro-inflammatory and pro-atherogenic agents [26], as well as enhancing cardiovascular risk.

NPs may also exert an inhibitory role on adipose tissue formation by modulating adipogenesis. Indeed, it has been reported that ANP inhibits the proliferation and differentiation of human visceral pre-adipocytes in adipocytes [27]. Hence NPs may act as protective factors towards the development of obesity and its metabolic complications.

On the other hand, obesity may decrease the bioactive levels of NPs via the increased expression of the clearance receptor NPR-C in adipose tissue. This may potentiate adipogenesis and lipid accumulation in obese patients. Animal and human adipose tissues express both NPR-A and the clearance receptor NPR-C [28] (Figure 1). The ratio between NPR-A and NPR-C expression, however, is reduced in adipose tissue of obese hypertensive patients [29], suggesting increased clearance of NPs in those patients. Interestingly, after the kidney, which is the principal clearance organ for NPs, adipose tissue has the greatest expression of NPR-C [28]. Fasting downregulates NPR-C expression in adipose tissue [30]. Moreover, in obese hypertensive patients exposed to a hypocaloric diet, ANP infusion induced natriuresis and a decrease in BP, as well as a significant increase in cGMP [31]. These findings support the hypothesis that the reduced NP levels observed in obese subjects and in patients with the MS are, in part, explained by the increased clearance of NPs in adipose tissue. In this regard, an inverse association between plasma NP levels and obesity has been described in the Framingham Heart Study [9] and other cohorts [32,33]. Previous reports have confirmed and extended this finding showing that low NP levels are associated with the MS and its individual components (waist circumference, fasting glucose, HDL-cholesterol and triacylglycerols), as well as with insulin resistance, even after adjustment for BMI (body mass index) [34]. In particular, it has been reported that an inverse association between NT-proBNP (N-terminal pro-BNP) levels and the MS is attributable to an inverse relationship between NT-proBNP and plasma lipids, serum insulin and BMI, independently of age and gender [35]. The reason underlying the reduction in NP levels in obesity and the MS has been attributed, at least in part, to increased clearance in adipose tissue, as mentioned above, although the importance of the NPR-C for clearance of NT-proBNP remains undefined [36].

It is not established whether low NP levels precede or follow the development of metabolic abnormalities. Nevertheless, several studies suggest that low NP levels could predispose to insulin resistance. This may occur mainly through activation of the RAAS [37], which promotes insulin resistance via multiple mechanisms in large part related to $\mathrm{AT}_{1}$ [AngII (angiotensin II) type 1] receptor stimulation. These mechanisms include inhibition of intracellular insulin signalling [38], enhanced oxidative stress [39], inflammation [40], reduced adipocyte differentiation [41], and decreased perfusion to the skeletal muscle and pancreas $[42,43]$. Furthermore, a direct influence of NPs on glucose metabolism has been reported [44,45]. Indeed, ANP infusion elevates plasma insulin levels [44] and inhibits glucagon secretion through a direct effect on pancreatic islets [45]. A direct anti-inflammatory effect of NPs has also been described [46-48]. This occurs through the reduction in inflammatory mediators such as TNF- $\alpha$ [46], COX-2 (cyclo-oxygenase-2) [47] and MCP-1 (monocyte chemoattractant protein-1) [48] (Figure 1). Moreover ANP directly stimulates the secretion of adiponectin [49], an adipocyte-specific anti-inflammatory hormone with insulin-sensitizing properties, and low levels of BNP are associated with low levels of adiponectin [50]. Finally, cGMP, the second messenger for NPs, plays a role in insulin-stimulated glucose transport [51]. 


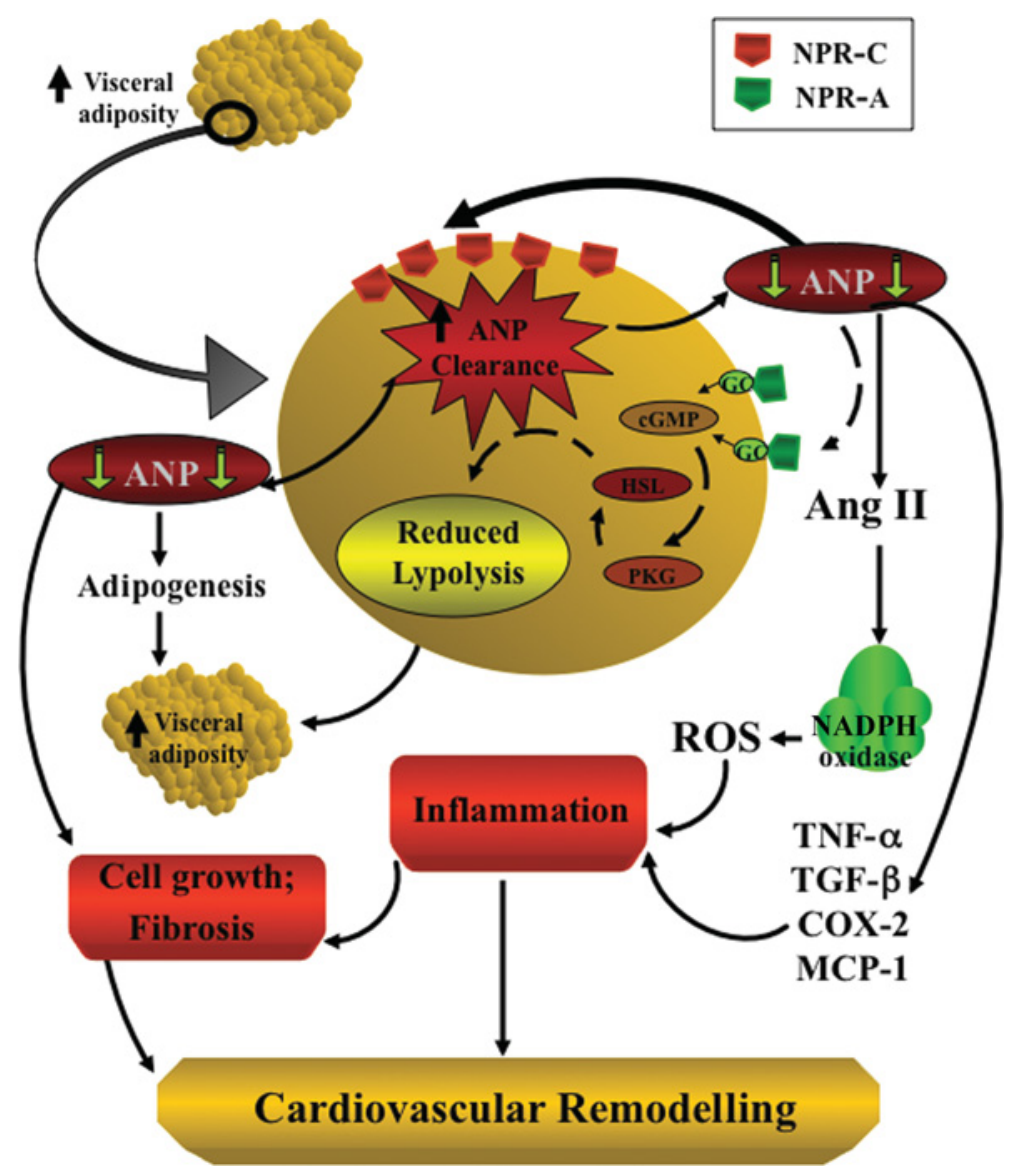

Figure I Low levels of NPs are involved in the pathophysiology of metabolic and cardiovascular complications $\overline{\mathrm{GC}}$, guanylate cyclase; HSL, hormone-sensitive lipase. Broken line, reduced effect.

Hence, under normal conditions, NPs may regulate adipose tissue formation and lipid utilization. On the other hand, in obese subjects, a dysregulation of the NP system has been described. Increased visceral adipose mass may reduce NP bioactive levels. This, in turn, may contribute to the maintenance of obesity and the development of insulin resistance, which are associated with a higher susceptibility of developing cardiovascular damage in patients with metabolic alterations.

\section{CARDIOVASCULAR DAMAGE IN DYSMETABOLIC PATIENTS: POSSIBLE INVOLVEMENT OF NPS}

The MS is associated with a global pro-inflammatory state in the cardiovascular system, as well as with impaired renal function and microalbuminuria, which can predispose to the development of cardiovascular and cerebrovascular disease, as well as to increased cardiovascular mortality.

Obesity and the MS are characterized by low circulating levels of NPs, as discussed above. Lower bioactive NP levels may contribute to the susceptibility of individuals with obesity and the MS in developing hypertension, vascular remodelling and inflammation, LVH [LV (left ventricular) hypertrophy] and dysfunction, as well as cardiovascular events. Indeed, NPs, within physiological levels, may play an important role in the counter-regulatory response to volume and pressure overload [52], as well as in preserving endothelial function and reducing inflammation and fibrosis in the cardiovascular system.

As elevation of BP is a key feature of cardiovascular damage in dysmetabolic conditions, such as obesity and the MS or diabetes, relationships between NPs and BP regulation require some discussion.

The well-known actions of ANP on salt and water balance and on BP homoeostasis have stimulated a large number of studies regarding its pathophysiological involvement in hypertension. Administration of ANP decreases BP levels in animal models and humans. Molecular genetic studies in animal models suggest a contribution of NPs to the development of hypertension, with the overexpression of ANP and BNP in transgenic mice reducing BP [53,54]. Inactivation of the ANP gene in mice is associated with the development of salt-sensitive hypertension and significant cardiac enlargement [55], 
and knockout of the NPR-A gene causes hypertension, although not a salt-sensitive type [56].

In fact, the ANP gene may act as a direct regulator of $\mathrm{BP}$ or as a contributory factor in certain forms of hypertension either by a deficiency in the peptide or by impaired biological function, which is dependent upon structural alterations of the gene. The increased frequency of hypertension in carriers of molecular variants of the ANP gene [57] supports the concept of a critical biological function of ANP in BP regulation. In particular, a contribution of an ANP gene variant to an increased predisposition to the early development of hypertension and its complications has been reported in a cohort of Caucasian subjects followed-up for 28 years [57].

Further evidence links NPs to BP control. For instance, NPs induce direct vasorelaxant actions through the activation of PKG (protein kinase G)-mediated ion channels in vascular smooth muscle cells, which induces membrane hyperpolarization [58]. In addition, the cGMPdependent activation of PKG decreases cytosolic free $\mathrm{Ca}^{2+}$ concentrations [59] by reducing $\mathrm{Ca}^{2+}$ release from intracellular stores, $\mathrm{Ca}^{2+}$ entry into the cell and increasing $\mathrm{Ca}^{2+}$ removal from the cytosol [60]. Furthermore, NPs might induce vasorelaxation through the activation of cGMP-regulated phosphodiesterases [61]. In particular, the activation of phosphodiesterase II results in the decrease in intracellular cAMP concentrations and an impairment of cAMP-mediated responses [62].

In addition, CNP may regulate BP by inducing a potent endothelium-independent vasodilatory effect on small resistance arteries via the activation of NPR-C and the opening of a G-protein-gated inwardly rectifying $\mathrm{K}^{+}$ channels [63].

Finally, NPs inhibit renin, vasopressin and aldosterone release, and, in humans, high plasma ANP levels decrease heart rate, central venous pressure and stroke volume [64]. This is also related to interactions between ANP and the baroreflex control of the circulation by modulating arterial and cardiopulmonary baroreceptor-mediated vascular responses $[65,66]$. ANP reduces sympathetic tone in the peripheral vasculature, probably by dampening baroreceptors, suppressing of the release of catecholamines from autonomic nerve endings and suppressing sympathetic outflow from the central nervous system [67-69].

In obese subjects with the MS, the levels of NPs are inappropriately low [9], and their release in response to volume loading is impaired [10]. Therefore obese subjects with the MS have a dysfunction in the NPs system and, thus, they may lack the protective effects of NPs on vessel structure and function, salt and water homoeostasis, and $\mathrm{BP}$ control. This may contribute to haemodynamic alterations and the development of hypertension in subjects with the MS or obesity who have increased plasma and stroke volumes, as well as increased cardiac output with inappropriately normal or slightly elevated vascular peripheral resistance. The reduced levels of NPs in subjects with the MS may also unmask the increased sympathetic nervous system activity present in obese patients with the MS [70,71]. Previous studies have shown the existence of a complex interplay among visceral adipocytes, the sympathetic nervous system and the RAAS. The increase in sympathetic nervous system activity in patients with the MS and/or obesity may participate in the dysregulation of the RAAS by enhancing the secretion of renin from the kidney and stimulating angiotensinogen expression in human adipocytes via cAMP-dependent mechanisms [72]. This, in turn, can contribute to the development and maintenance of hypertension in obese dysmetabolic patients.

Visceral adiposity and NPs are inversely related and may participate in the development of vascular inflammation. NPs may modulate cell growth and inflammation within the heart and the vascular wall in disorders such as atherosclerosis, hypertension and post-angioplasty restenosis, thus contributing to the modulation of cardiovascular remodelling [73]. NPs exert antimitogenic activity on both the cardiovascular and other organ systems, and exert antiproliferative effects on vascular cells [74-76], mainly through a cGMP-dependent mechanism. NPs also exert several anti-inflammatory and antifibrotic effects. ANP directly inhibits the actions of COX-2 [47] and iNOS (inducible NO synthase) [77], reduces the production of macrophage-derived TNF- $\alpha$ [46] and interferes with the TNF- $\alpha$-induced activation of the pro-inflammatory nuclear factor $\mathrm{NF}-\kappa \mathrm{B}$ (nuclear factor $\kappa \mathrm{B})$ [78]. ANP blocks TGF- $\beta$ (transforming growth factor- $\beta$ )-induced fibroblast differentiation, proliferation and collagen synthesis in murine hearts [79]. Moreover, BNP inhibits the profibrotic actions of TGF- $\beta$, and $\mathrm{CNP}$ reduces the proliferation of cardiac fibroblasts and decreases the collagen deposition in the heart [80].

Visceral adipose tissue produces large amounts of ROS (reactive oxygen species) and pro-inflammatory cytokines [81] [for example, IL-6 (interleukin-6), which induces CRP (C-reactive protein) secretion] [25]. Visceral adipose tissue is infiltrated by macrophages, which are also stimulated to produce inflammatory mediators such as TNF- $\alpha$. Moreover, circulating adiponectin levels are decreased in obese subjects. This has been associated with the progression of atherosclerotic lesions [82] in dysmetabolic subjects.

Therefore, in metabolic patients, increased visceral adipose tissue, along with the reduced levels of NPs, may contribute to the development of a peripheral pro-inflammatory state, which may play an important role in the development of atherosclerosis in patients with the MS.

Endothelial dysfunction is present in patients with the MS and is a predictor of cardiovascular morbidity and mortality [1,2]. Low levels of NPs in dysmetabolic patients may contribute to the development of endothelial dysfunction. Indeed, ANP contributes to endothelial 
function in the general population, as it correlates with brachial artery endothelial function [83]. At low concentrations, ANP increased human endothelial cell number and migration [84]. This effect is mediated by cGMP-dependent MAPK (mitogen-activated protein kinase) activation and appears particularly effective in the regeneration of endothelial cells after injury in atherosclerosis [84]. In addition, BNP-mediated vasorelaxation is endothelium-independent and may be impaired in experimental atherosclerosis [76]. In the rabbit, longterm oral inhibition of NEP preserves relaxation to BNP in atherosclerosis, while attenuating atheroma formation and maintaining endothelial function, independent of decreases in serum cholesterol.

NPs induce vasorelaxant effects in the coronary circulation [85]. In particular, experimental studies have shown that the vasodilator actions of ANP are especially relevant in epicardial coronary arteries [86]. Similar effects have been reported for BNP in humans [87], and for CNP in porcine and human coronary arteries $[88,89]$. Moreover, ANP and BNP increase rapidly after myocardial infarction [90], and the rapid release of NPs following infarction has been suggested to provide a protective action on the ischaemic myocardium [61]. BNP significantly reduces infarct size in a concentrationdependent manner, possibly through the activation of NO-dependent soluble guanylate cyclase. [91]. Moreover, ANP infusion immediately after coronary angioplasty in patients with acute myocardial infarction has been able to prevent LV dilation and remodelling more efficiently than isosorbide dinitrate [86]. On the other hand, in patients with CAD, low levels of NT-proBNP are inversely correlated with BMI, with the NTproBNP levels not elevated in patients with CAD and high BMI [92]. Thus low NP levels may contribute to the pro-inflammatory state, as well as to the endothelial dysfunction and reduced coronary reserve in obese patients with the MS. This may predispose to the development of atherosclerosis and CAD in dysmetabolic patients.

BNP has been investigated extensively as a marker of LV dysfunction and as a prognostic factor in patients affected by congestive heart failure [93]. Increased ANP plasma levels have been proposed as a marker of LVH [94]; however, further studies have shown that ANP may directly modulate cardiac mass by inhibiting a variety of hypertrophic cellular signalling pathways through NPR-A stimulation. In vitro, ANP induced MAPKP-1 (MAPK phosphatase-1) [95], a dual serine/threonine and tyrosine phosphatase that selectively inactivates MAPK family members, which are involved in hypertrophy and cell proliferation. ANP inhibits the noradrenaline (norepinephrine)-induced growth of cardiomyocytes through a cGMP-mediated inhibition of $\mathrm{Ca}^{2+}$ influx [96], and inhibits the production of NADPH-oxidasemediated ROS, which are the key mediators of cell growth and inflammation in cardiovascular remodelling
[97]. Furthermore, a ANP gene promoter variant, which was associated with reduced circulating NT-proANP (N-terminal proANP) levels, correlated with increased cardiac mass, independently of all anthropometric and clinical parameters, and pharmacological treatments [98].

We have reported previously that low circulating ANP levels were significantly inversely related to cardiac mass in hypertensive patients with the MS [99]. Thus the ANP/NPR-A system may offer a novel countervailing mechanism towards the hypertrophic growth response in the heart [100]. Nonetheless, low ANP levels may predispose, at least in part, to the development of fibrosis and cardiovascular remodelling.

The development of LVH, which is an independent predictor of adverse cardiovascular events, is enhanced in hypertensive patients with the MS, being related to both high BP and central obesity [101-103]. Several metabolic and hormonal factors (including dyslipidaemia, insulin resistance, AngII and leptin) may contribute to the structural and functional alterations of the LV wall in hypertensive patients with the MS [104]. Experimental and clinical studies have described a direct contributory effect of ANP to cardiac remodelling particularly in hypertensive subjects with MS, being LVH favoured by low levels of this antihypertrophic hormone [98,105]. In patients with the MS, it has been reported that low ANP levels are inversely related to LV mass independently by all of the known components of the MS [99]. This supports the hypothesis that dysregulation of NPs is involved in the pathogenesis of LVH in patients with the MS, underlying the protective role of NPs in cardiovascular remodelling and possibly in the prevention of myocardial dysfunction in metabolic subjects.

\section{CONCLUSIONS}

Several lines of evidence have shown that NPs may positively modulate lipid metabolism and insulin sensitivity, in part by preventing lipid accumulation in adipose tissue. Moreover, NPs have emerged as critical factors for the regulation of cardiovascular function through diuretic, natriuretic and vasorelaxant effects, as well as antiproliferative and anti-inflammatory actions. Plasma levels of NPs are inversely related to the increase in visceral adipose mass which is one of the key features of the MS. A defective NP system (mainly due to the reduced plasma levels of bioactive NPs in metabolic patients) may in turn contribute to increased visceral fat accumulation. Furthermore, an altered regulation of the production, clearance and function of NPs may possibly contribute to the development of hypertension, cardiovascular remodelling, atherosclerosis and CAD in patients with obesity and the MS.

In this regard, the availability of drugs that promote the actions of NPs, such as the orally active antagonists of NP breakdown by NEP, may theoretically represent 
an attractive therapeutic option for patients with the MS and cardiovascular disease. Research in this field has led to the development of dual inhibitors of NEP and ACE (angiotensin-converting enzyme) (the vasopeptidase inhibitors) [106]. By simultaneously inhibiting the RAAS and potentiating the action of NPs and the kinin system, vasopeptidase inhibitors reduce vasoconstriction, enhance vasodilation and improve local blood flow. Within the blood vessel wall, this leads to a reduction in vasoconstrictor and proliferative mediators, such as AngII, and increased local levels of bradykinin and, in turn, NO and NPs. Vasopeptidase inhibitors have provided encouraging results on BP control and in reducing pulse pressure and aortic stiffness in different subsets of hypertensive patients [107], and in improved cardiac function and lower mortality/morbidity and prevalence of renal dysfunction compared with patients treated with an ACEI (ACE inhibitor) [108]. However, the introduction of vasopeptidase inhibitors in clinical practice is still limited due to the greater rates of angioedema, particularly in black subjects, which may be related to higher levels of bradykinin and a higher risk in susceptible individuals. Furthermore, addition of NEP inhibition to ACE inhibition reduces Ang-(1-7) (angiotensin 1-7) levels and may increase ET levels, which may counteract the benefits of ACE inhibition [109].

In addition, human recombinant NPs have been tested with evidence of favourable effects on the modulation of fluid and electrolyte balance, vascular smooth muscle tone, and the regulation of coronary blood flow, myocardial perfusion and proliferative responses during myocardial and vascular remodelling [110]. Further clinical studies are necessary to evaluate risks and benefits of the clinical use of these novel pharmaceutical agents for the prevention and treatment of cardiovascular disease, particularly in dysmetabolic patients.

\section{REFERENCES}

1 Dandona, P., Ajada, A., Chaudhuri, A., Mohanty, P. and Garg, R. (2005) Metabolic syndrome: a comprehensive perspective based on interactions between obesity, diabetes and inflammation. Circulation 111, 1448-1454

2 Alberti, K. G. and Zimmet, P. Z. (1998) Definition, diagnosis and classification of diabetes mellitus and its complications. Part 1: diagnosis and classifications of diabetes mellitus provisional report of a WHO consultation. Diabetic Med. 15, 539-553

3 Grundy, S. M., Brewer, Jr, H. B., Cleeman, J. L., Smith, Jr, S. C. and Lenfant, C. (2004) Definition of metabolic syndrome: report of the National Heart, Lung and Blood Institute/American heart association conference on scientific issues related to definition. Circulation 109 , 433-438

4 Einhorn, D., Reaven, G. M., Cobin, R. H., Ford, E., Ganda, O. P., Handelsman, Y., Hellman, R., Jellinger, P. S., Kendall, D., Krauss, R. M., Neufeld, N. D. et al. (2003) American College of Endocrinology position statement on the insulin resistance syndrome. Endocr. Pract. 9, 237-252
5 Alberti, K. G., Zimmet, P. and Shaw, J. (2005) IDF epidemiology task force consensus group. The metabolic syndrome-a new worldwide definition. Lancet 266, 1059-1062

6 Carr, D. B., Utzschneider, K. M., Hull, R. L., Kodama, K., Retzlaff, B. M., Brunzell, J. D., Shofer, J. B., Fish, B. E., Knopp, R. H. and Kahn, S. E. (2004) Intra-abdominal fat is a major determinant of the National Cholesterol Educational Program Adult Panel III criteria for the metabolic syndrome. Diabetes 53, 2087-2094

7 Rubattu, S., Sciarretta, S., Valenti, V., Stanzione, R. and Volpe, M. (2008) Natriuretic peptides: an update on bioactivity, potential therapeutic use and implication in cardiovascular diseases. Am. J. Hypertens. 21, 733-741

8 Licata, G., Volpe, M., Scaglione, R. and Rubattu, S. (1994) Salt-regulating hormones in young normotensive obese subjects. Effects of saline load. Hypertension 23, I20-I24

9 Wang, T. J., Larson, M. G., Levy, D., Benjamin, E. J., Leip, E. P., Wilson, P. W. and Wasan, R. S. (2004) The impact of obesity on plasma natriuretic peptide levels: the Framinghan Heart Study. Circulation 109, 594-600

10 Goodfriend, T. L., Kelley, D. E., Goodpaster, B. H. and Winters, S. J. (1999) Visceral obesity and insulin resistance are associated with plasma aldosterone levels in women. Obes. Res. 7, 355-362

11 Savoia, C. and Schiffrin, E. L. (2004) Significance of recently identified peptides in hypertension: endothelin, natriuretic peptides, adrenomedullin, leptin. Med. Clin. North Am. 88, 39-62

12 Koller, K. J. and Goeddel, D. V. (1992) Molecular biology of the natriuretic peptides and their receptors. Circulation 86, 1081-1088

13 Anand-Srivastava, M. B., Sairam, M. R. and Cantin, M. (1990) Ring-deleted analogs of atrial natriuretic factor inhibit adenylate cyclase/cAMP system. Possible coupling of clearance atrial natriuretic factor receptors to adenylate cyclase/cAMP signal transduction system. J. Biol. Chem. 265, 8566-8572

14 Maack, T., Tikonova, L. N., Friedman, O. and Cohen, D. (1996) Functional properties and dynamics of natriuretic peptide receptors. Proc. Soc. Exp. Biol. Med. 213, 109-116

15 Nakao, K., Sugawara, A., Morii, N., Sakamoto, M., Yamada, T., Itoh, H., Shiono, S., Saito, Y., Nishimura, K. and Ban, T. (1986) The pharmacokinetics of $\alpha$-human atrial natriuretic polypeptide in healthy subjects. Eur. J. Clin. Pharmacol. 31, 101-103

16 Sengenes, C., Bouloumie, A., Hauner, H., Berlan, M., Busse, R., Lofantan, M. and Galitzky, J. (2003) Involvement of a cGMP-dependent pathway in a natriuretic peptide-mediated hormone sensitive lipase phosphorylation in human adipocytes. J. Biol. Chem. 278, 48617-48626

17 Birkenfeld, A. L., Boschmann, M., Moro, C., Adams, F., Heusser, K., Franke, G., Berlan, M., Luft, F. C., Lafontan, M. and Jordan, J. (2005) Lipid mobilization with physiological atrial natriuretic peptide concentrations in human. J. Clin. Endocrinol. Metab. 90, 3622-3628

18 Moro, C., Galintzky, J., Sengenes, C., Crampes, F., Lafontan, M. and Berlan, M. (2004) Functional and pharmacological characterization of the natriuretic peptide-dependent lipolytic pathway in human fat cells. J. Pharmacol. Exp. Ther. 308, 984-992

19 Sengenes, C., Stich, V., Berlan, M., Hejnova, J., Lafontan, M., Pariskova, Z. and Galitzky, J. (2002) Increased lipolysis in adipose tissue and lipid mobilization to natriuretic peptides during low-calorie diet in obese women. Int. J. Obes. Relat. Metab. Disord. 26, 24-32

20 Moro, C., Crampes, F., Sengenes, C., De Glisezinski, I., Galitzky, J., Thalamas, C., Lafontan, M. and Berlan, M. (2004) Atrial natriuretic peptide contributes to physiological control of lipid mobilization in humans. FASEB J. 18, 908-910

21 Huss, J. M. and Kelly, D. P. (2004) Nuclear receptor signalling and cardiac energetics. Circ. Res. 95, 568-578

22 Nisoli, E., Clementi, E., Paolucci, C., Cozzi, V., Tonello, C., Sciorati, C., Bracale, R., Valerio, A., Francolini, M. Moncada, S. and Carruba, M. O. (2003) Mitochondrial biogenesis in mammals: the role of endogenous nitric oxide. Science $\mathbf{2 9 9}, 896-899$ 
23 Pilz, S., Scharnagi, H., Tiran, B., Seelhorst, U., Wellnitz, B., Bohem, B. O., Schaefer, J. R. and März, W. (2006) Free fatty acids are independently associated with all-cause and cardiovascular mortality in subjects with coronary artery disease. J. Clin. Endocrinol. Metab. 91, 2542-2547

24 Bergman, R. N., Kim, S. P., Hsu, I. R., Catalano, K. J., Chiu, J. D., Kabir, M., Richey, J. M. and Ader, M. (2007) Abdominal obesity: role in the pathophysiology of metabolic disease and cardiovascular risk. Am. J. Med. $120, \mathrm{~S} 3-\mathrm{S} 8$

25 Despres, J. P. and Lemieux, I. (2006) Abdominal obesity and metabolic syndrome. Nature 444, 881-887

26 Navab, M., Anantharamaiah, G. M. and Fogelman, A. M. (2005) The role of high density lipoprotein in inflammation. Trends Cardiovasc. Med. 15, 158-161

27 Sarzani, R., Marcucci, P., Salvi, F., Bordicchia, M. Espinosa, E., Mucci, L., Lorenzetti, B., Minardi, D., Muzzonigro, G., Dessì-Fulgheri, P. and Rappelli, A. (2008) Angiotensin II stimulates and atrial natriuretic peptide inhibits human visceral adipocyte growth. Int. J. Obes. 32, 259-267

28 Sarzani, R., Dessi-Fulgheri, P., Paci, M. V., Espinosa, E. and Rappelli, A. (1996) Expression of natriuretic peptides receptors in human adipose tissues. J. Endocrinol. Invest. $19,581-585$

29 Dessi-Fulgheri, P., Sarzani, R., Tamburrini, P., Moraca, A., Espinosa, E., Cola, G., Giantomassi, L. and Rappelli, A. (1997) Plasma atrial natriuretic peptide and natriuretic peptide receptor gene expression in adipose tissue of normotensive and hypertensive obese patients. J. Hypertens. 15, 1696-1699

30 Sarzani, R., Paci, M. V., Zingareti, C. M., Pierleoni, C., Cinti, S., Cola, G., Rappelli, A. and Dessì-Fulgheri, P.' (1995) Fasting inhibits natriuretic peptides clearance receptor expression in rat adipose tissue. J. Hypertens. 13, 1241-1246

31 Dessì-Fulgheri, P., Sarzani, R., Serenelli, M., Tamburrini, P., Spagnolo, D., Giantomassi, L., Espinosa, E. and Rappelli, A. (1999) Low calorie diet enhances renal, hemodynamic and humoral effects of exogenous atrial natriuretic peptide in obese hypertensives. Hypertension $33,658-662$

32 Das, S. R., Drazner, M. H., Dries, D. L., Vega, G. L., Stanek, H. G., Abdullah, S. M., Canham, R. M. Chung, A. K., Leonard, D., Wians, Jr, F. H. and De Lemos, J. A. (2005) Impact of body mass and body composition on circulating levels of natriuretic peptides: results from the Dallas Heart Study. Circulation 112, 2163-2068

33 Mehra, M. R., Uber, P. A., Park, M. H., Scott, R. L., Ventura, H. O., Harris, B. C. and Fronlich, E. D. (2004) Obesity and suppressed B-type natriuretic peptide levels in heart failure. J. Am. Coll. Cardiol. 43, 1590-1595

34 Wang, T. J., Larson, M. G., Keyes, M. J., Levy, D., Benjamin, E. L. and Vasan, R. S. (2007) Association of plasma natriuretic peptide levels with metabolic risk factors in ambulatory individuals. Circulation 115, $1345-1353$

35 Olsen, M. H., Hansen, T. W., Christensen, M. K., Gustafsson, F., Rasmussen, S., Watchell, K., Borch-Johnsen, K., Ibsen, H., Jorgensen, T. and Hildebrandt, P. (2005) N-terminal pro brain natriuretic peptide is inversely related to metabolic cardiovascular risk factors and the metabolic syndrome. Hypertension 46, 660-666

36 Hall, C. (2004) Essential biochemistry and physiology of (NT-pro)BNP. (2004) Eur. J. Heart Failure 6, 257-260

37 Johnston, C. I., Hodsman, P. G., Kohzuki, M., Casley, D. J., Fabris, B. and Phillips, P. A. (1989) Interaction between atrial natriuretic peptide and the renin angiotensin aldosterone system: endogenous antagonists. Am. J. Med. 87, 24S-28S

38 Velloso, L. A., Folli, F., Sun, X. J., White, M. F., Saad, M. J. and Kahn, C. R. (1996) Cross-talk between the insulin and angiotensin signaling systems. Proc. Natl. Acad. Sci. U.S.A. 93, 12490-12495
39 Rajagopalan, S., Kurz, S., Munzel, T., Tarpey, M., Freeman, B. A., Griendling, K. K. and Harrison, D. G. (1996) Angiotensin II-mediated hypertension in the rat increases vascular superoxide production via membrane $\mathrm{NADH} / \mathrm{NADPH}$ oxidase activation: contribution to alterations of vasomotor tone. J. Clin. Invest. 97, 1916-1923

40 Fliser, D., Buchholz, K. and Haller, H. (2004) Antiinflammatory effects of angiotensin II subtype 1 receptor blockade in hypertensive patients with microinflammation. Circulation 110, 1103-1107

41 Janke, J., Engeli, S., Gorzelniak, K., Luft, F. C. and Sharma, A. M. (2002) Mature adipocytes inhibit in vitro differentiation of human preadipocytes via angiotensin type 1 receptors. Diabetes 51, 1699-1707

42 Henriksen, E. J. and Jacob, S. (2003) Angiotensin converting enzyme inhibitors and modulation of skeletal muscle insulin resistance. Diabetes Obes. Metab. 5, 214-222

43 Carlsson, P. O., Berne, C. and Jansson, L. (1998) Angiotensin II and the endocrine pancreas: effects on islet blood flow and insulin secretion in rats. Diabetologia 41, $127-133$

44 Uehlinger, D. E., Weidmann, P., Gnadinger, M. P., Hasler, L., Bachmann, C., Shaw, S., Hellmuller, B. and Lang, R. E. (1986) Increase in circulating insulin induced by atrial natriuretic peptide in normal humans. J. Cardiovasc. Pharmacol. 8, 1122-1129

45 Verspohl, E. J. and Bernemann, I. K. (1996) Atrial natriuretic peptide (ANP)-induced inhibition of glucagon secretion: mechanism of action in isolated rat pancreatic islets. Peptides 17, 1023-1029

46 Tsukagoshi, H., Shimizu, Y., Kawata, T., Hisada, T., Shimitzu, Y., Iwamae, S., Ishizuka, T., Izuka, K., Dobashi, K. and Mori, M. (2001) Atrial natriuretic peptide inhibits tumor necrosis factor- $\alpha$ production by interferon- $\gamma$-activated macrophages via suppression of p38 mitogen-activated protein kinase and nuclear factor $-\kappa \mathrm{B}$ activation. Regul. Pept. 99, 21-29

47 Kiemer, A. K., Lehner, M. D., Hartung, T. and Vollmar, A. M. (2002) Inhibition of cyclooxygenase- 2 by natriuretic peptides. Endocrinology 143, 846-852

48 Weber, N. C., Blumenthal, S. B., Hartung, T., Vollmar, A. M. and Kiemer, A. K. (2003) ANP inhibits TNF- $\alpha$-induced endothelial MCP-1 expression: involvement of p38 MAPK and MKP-1. J. Leukocyte Biol. 74, 932-941

49 Moro, C., Klimcakova, E., Lolmede, K., Berlan, M., Lafontan, M., Stich, V., Bouloumié, A., Galitzky, J., Arner, P. and Langin, D. (2007) Atrial natriuretic peptide inhibits the production of adipokines and cytokines linked to inflammation and insulin resistance in human subcutaneous adipose tissue. Diabetologia 50, 1038-1047

50 Kistorp, C., Faber, J., Galatius, S., Gustafsson, F., Frystyk, J., Flyvbjerg, A. and Hildebrandt, P. (2005) Plasma adiponectin, body mass index and mortality in patients with chronic heart failure. Circulation 112, 1756-1762

51 Bergandi, L., Silvagno, F., Russo, I., Riganti, C., Anfossi, G., Aldieri, E., Ghigo, D., Trovati, M. and Bosia, A. (2003) Insulin stimulates glucose transport via nitric oxide/cyclic GMP pathway in human vascular smooth muscle cells. Arterioscler. Thromb. Vasc. Biol. 23, 2215-2221

52 Leoncini, G., Ratto, E., Viazzi, F., Vaccaro, V., Parodi, D., Parodi, A., Falqui, V., Tomolillo, C., Deferrari, G. and Pontremoli, R. (2005) Metabolic syndrome is associated with early signs of organ damage in nondiabetic, hypertensive patients. J. Intern. Med. 257, 454-460

53 Steinhelper, M. E., Cochrane, K. L. and Field, L. J. (1990) Hypotension in transgenic mice expressing atrial natriuretic factor fusion genes. Hypertension 16, 301-307

54 Ogawa, Y., Itoh, H., Tamura, N., Suga, S., Yoshimasa, T., Uehira, M., Matsuda, S., Shiono, S., Nishimoto, H. and Nakao, K. (1994) Molecular cloning of the complementary DNA and gene that encode mouse brain natriuretic peptide and generation of transgenic mice that overexpress the brain natriuretic peptide gene J. Clin. Invest. 93, 1911-1921 
55 Jhon, S. W. M., Krege, J. H., Oliver, P. M., Hagaman, J. R., Hodgin, J. B., Pang, S., Flynn, T. G. and Smithies, O. (1995) Genetic decreases in atrial natriuretic peptide and salt sensitive hypertension. Science 267, 679-681

56 Lopez, M. J., Wong, S. K., Kishimoto, I., Dubois, S., Mach, V., Friesen, J., Garbers, D. L. and Beuve, A. (1995) Salt-resistant hypertension in mice lacking the guanyl cyclase-A receptor for atrial natriuretic peptide. Nature 378, 65-68

57 Rubattu, S., Evangelista, A., Barbato, D., Barba, G., Stanzione, R., Iacone, R., Volpe, M. and Strazzullo, P. (2007) Atrial natriuretic peptide (ANP) gene promoter variant and increased susceptibility to early development of hypertension in humans. J. Hum. Hypertens. 21, 822-824

58 Dora, K. A., Garland, C. J., Kwan, H. Y. and Yao, X. (2001) Endothelial cell protein kinase G inhibits release of EDHF through a PKG-sensitive cation channel. Am. J. Physiol. Heart Circ. Physiol. 280, H1272-H1277

59 Rosado, J. A., Porras, T., Conde, M. and Sage, S. O. (2001) Cyclic nucleotides modulate store-mediated calcium entry through the activation of protein tyrosine phosphorylation and altered actin polymerization in human platelets. J. Biol. Chem. 276, 15666-15675

60 Geiger, J., Nolte, C., Butt, E., Sage, S. O. and Walter, U. (1992) Role of cGMP and cGMP-dependent protein kinase in nitrovasodilator inhibition of agonist-evoked calcium elevation in human platelets. Proc. Natl. Acad. Sci. U.S.A. 89, 1031-1035

61 D’Souza, S. P., Davis, M. and Baxter, G. F. (2004) Autocrine and paracrine actions of natriuretic peptides in the heart. Pharmacol. Ther. 101, 113-129

62 Whalin, M. E., Scammell, J. G., Strada, S. J. and Thompson, W.J. (1991) Phosphodiesterase II, the cGMP-activatable cyclic nucleotide phosphodiesterase, regulates cyclic AMP metabolism in PC12 cells. Mol. Pharmacol. 39, 711-717

63 Chauhan, S. D., Nilsson, H., Ahluwalia, A. and Hobbs, A. J. (2003) Release of C-type natriuretic peptide accounts for the biological activity of endothelium-derived hyperpolarizing factor. Proc. Natl. Acad. Sci. U.S.A. 100, 1426-1431

64 Volpe, M., Cuocolo, A., Vecchione, F., Lembo, G., Pignalosa, S., Condorelli, M. and Trimarco, B. (1989) Influence of volume expansion on hemodynamic effects of atrial natriuretic factor in rabbits. Am. J. Physiol. 256, $\mathrm{H} 852-\mathrm{H} 858$

65 Volpe, M., Lembo, G., Condorelli, G. L., De Luca, N., Lamenza, F., Indolfi, C. and Trimarco, B. (1990) Converting enzyme inhibition prevents the effect of atrial natriuretic factor on baroreflex responses in humans. Circulation 82, 1214-1221

66 Volpe, M., De Luca, N., Cappelli-Bigazzi, M., Vecchione, F., Lembo, G., Condorelli, M. and Trimarco, B. (1988) Atrial natriuretic factor potentiates forearm reflex vasoconstriction induced by cardiopulmonary receptor deactivation in man. Circulation 77, 849-855

67 Schultz, H. D., Gardner, D. G., Deschepper, C. F., Coleridge, H. M. and Coleridge, J. C. (1988) Vagal C fibre blockade abolishes sympathetic inhibition by atrial natriuretic factor. Am. J. Physiol. 155, R6-R13

68 Yang, R. H., Jin, H. K., Wyss, J. M., Chen, Y. F. and Oparil, S. (1992) Pressor effect of blocking atrial natriuretic peptide in nucleus tractus solitari. Hypertension 19, 198-205

69 Saper, C. B., Standaert, D. G., Currie, M. G., Schwartz, D., Geller, D. M. and Needleman, P. (1985) Atriopeptin immunoreactive neurons in the brain: presence in cardiovascular regulatory areas. Science 227, 1047-1049

70 Aneja, A., El-Atat, F., McFarlane, S. I. and Sowers, J. R. (2004) Hypertension and obesity. Recent Progr. Horm. Res. 59, 169-205

71 Mancia, G., Bousquet, P., Elghozi, J. L., Esler, M., Grassi, G., Julius, S., Reid, J. and van Zwieten, P. A. (2007) The sympathetic nervous system and the metabolic syndrome. J. Hypertens. 25, 909-920
72 Serazin, V., Dos Santos, E., Morot, M. and Giudicelli, Y. (2004) Human adipose angiotensinogen gene expression and secretion are stimulated by cyclic AMP via increased DNA cyclic AMP responsive element binding activity. Endocrine 25, 97-104

73 Barbato, E., Rubattu, S., Bartunek, J., Berni, A., Sarno, G., Vanderheyden, M., Delrue, L., Zardi, D., Pace, B., De Bruyne, B. et al. (2009) Human coronary atherosclerosis modulates cardiac natriuretic peptide release. Atherosclerosis, doi:10.1016/j.atherosclerosis.2009.01.033

74 Itoh, H., Pratt, R. E. and Dzau, V. J. (1990) Atrial natriuretic polypeptide inhibits hypertrophy of vascular smooth muscle cells. J. Clin. Invest. 86, 1690-1697

75 Furuya, M., Aisaka, K., Miyazaki, T., Honbou, N., Kawashima, K., Ohno, T., Tanaka, S., Minamino, N., Kangawa, K. and Matsuo, H. (1993) C-type natriuretic peptide inhibits intimal thickening after vascular injury. Biochem. Biophys. Res. Commun. 193, 248-253

76 Schirger, J. A., Grantham, J. A., Kullo, I. J., Jougasaki, M., Wennberg, P. W., Chen, H. H., Lisy, O., Miller, V., Simari, R. D. and Burnett, Jr, J. C. (2000) Vascular actions of brain natriuretic peptide: modulation by atherosclerosis and neutral endopeptidase inhibition. J. Am. Coll. Cardiol. 35, 796-801

77 Kiemer, A. K. and Vollmar, A. M. (1998) Autocrine regulation of inducible nitric-oxide synthase in macrophages by atrial natriuretic peptide. J. Biol. Chem. 273, 13444-13451

78 Kiemer, A. K., Weber, N. C. and Vollmar, A. M. (2002) Induction of $\mathrm{I} \kappa \mathrm{B}$ : atrial natriuretic peptide as a regulator of the NF- $\kappa \mathrm{B}$ pathway. Biochem. Biophys. Res. Commun. 295, 1068-1076

79 Kapoun, A. M., Liang, F., O’young, G., Damm, D. L., Quon, D., White, R. T., Munson, K., Lam, A., Schreiner, G. F. and Protter, A. A. (2004) B-type natriuretic peptide exerts broad functional opposition to transforming growth factor- $\beta$ in primary human cardiac fibroblasts fibrosis, myofibroblast conversion, proliferation, and inflammation. Circ. Res. 94, 453-461

80 Horio, T., Tokudome, T., Maki, T., Yoshihara, F., Suga, S., Nishikimi, T., Kojima, M., Kawano, Y. and Kangawa, K. (2003) Gene expression, secretion and autocrine action of C-type natriuretic peptide in cultured adult rat cardiac fibroblasts. Endocrinology 144, 2279-2284

81 Furukawa, S., Fujita, T., Shimabukuro, M., Iwaki, M., Yamada, Y., Nakajima, Y., Nakayama, O., Mikishima, M., Matsuda, M. and Shimomura, I. (2004) Increased oxidative stress in obesity and its impact on metabolic syndrome. J. Clin. Invest. 114, 1752-1761

82 Maahs, D. M., Ogden, L. G., Kinney, G. L., Wadwa, P., Snell-Bergeon, J. K., Dabelea, D., Hokanson, J. E., Ehrlich, J., Eckel, R. H. and Rewers, M. (2005) Low plasma adiponectin levels predict progression of coronary artery calcification. Circulation 111, 747-753

83 Kathiresan, S., Gona, P., Larson, M. G., Vita, J. A., Mitchell, G. F., Tofler, G. H., Levy, D., Newton-Cheh, C., Wang, T. J., Benjamin, E. J. and Vasan, R. S. (2006) Cross-sectional relations of multiple biomarkers from distinct biological pathways to brachial artery endothelial function. Circulation 113, 938-945

84 Kooh, H., Itoh, H., Choi, B. S., Sawada, N., Doi, K., Hwang, T. J., Kim, K. K., Arai, H., Baik, Y. H. and Nakao, K. (2003) Physiological concentration of atrial natriuretic peptide induces endothelial regeneration in vitro. Am. J. Physiol. Heart Circ. Physiol. 284, H1388-H1397

85 Supaporn, T., Wennberg, P. W., Wei, C. M., Kinoshita, M., Matsuda, Y. and Burnett, Jr, J. C. (1996) Role of the endogenous natriuretic peptide system in the control of basal coronary vascular tone in dogs. Clin. Sci. 90, 357-362

86 Kasama, S., Toyama, T., Hatori, T., Sumino, H., Kumakura, H., Takayama, Y., Ichikawa, S., Suzuki, T. and Kurabayashi, M. (2007) Effects of intravenous atrial natriuretic peptide on cardiac sympathetic nerve activity and left ventricular remodeling in patients with first anterior acute myocardial infarction. J. Am. Coll. Cardiol. $49,667-674$ 
87 Okumura, K., Yasue H., Fujii H., Kugiyama, K., Matsuyama, K., Yoshimura, M., Jougasaki, M., Kikuta, K., Kato, H. and Tanaka, H. (1995) Effects of brain (B-type) natriuretic peptide on coronary artery diameter and coronary hemodynamic variables in humans: comparison with effects of systemic hemodynamic variables. J. Am. Coll. Cardiol. 25, 342-348

88 Wei, C. M., Hu, S., Miller, V. M. and Burnett, Jr, J. C. (1994) Vascular actions of C-type natriuretic peptide in isolated porcine coronary arteries and coronary vascular smooth muscle cells. Biochem. Biophys. Res. Commun. 205, 765-771

89 Wiley, K. E. and Davenport, A. P. (2001) Physiological antagonism of endothelin-1 in human conductance and resistance coronary artery. Br. J. Pharmacol. 133, 568-574

90 Toth, M., Vuorinen, K. H., Vuoltheenaho, O., Hassinen, I. E., Uusimaa, P. A., Leppaluoto, J. and Ruskoaho, H. (1994) Hypoxia stimulates release of ANP and BNP from perfused rat ventricular myocardium. Am. J. Physiol. 266, H1572-H1580

91 D’Souza, S. P., Yellon, D. M., Martin, C., Schulz, R., Heusch, G., Onody, A., Ferdinandy, P. and Baxter, G. F. (2003) B-type natriuretic peptide limits infarct size in rat isolated hearts via $\mathrm{K}_{\text {ATP }}$ channel opening. Am. J. Physiol Heart Circ. Physiol. 284, H1592-H1600

92 Hong, S. N., Ahn, Y., Yoon, N. S., Moon, J. Y., Kim, K. H., Hong, Y. J., Park, H. W., Kim, J. H., Jeong, M. H., Cho, J. C. et al. (2008) N-terminal pro-B-tye natriuretic peptide level is depressed in patients with significant coronary artery disease who have high body mass index. Int. Heart J. 49, 403-412

93 Berger, R., Huelsman, M., Strecker K., Bojic, A., Moser, P., Stanek, B. and Pacher, R. (2002) B-type natriuretic peptides predicts sudden death in patients with chronic heart failure. Circulation 105, 2392-2397

94 Nishikimi, T., Yoshihara, F., Morimoto, A., Ishikawa, K., Ishimitsu, T., Saito, Y., Kangawa, K., Matsuo, H., Omae, T. and Matsuoka, H. (1996) Relationship between left ventricular geometry and natriuretic peptide levels in essential hypertension. Hypertension 28, 22-30

95 Hayashi, D., Kudoh, S., Shiojima, I., Zou, Y., Harada, K., Shimoyama, M., Imai, Y., Monzen, K., Yamazaki, T., Yazaki, Y. et al. (2004) Atrial natriuretic peptide inhibits cardiomyocyte hypertrophy through mitogen-activated protein kinase posphatase-1. Biochem. Biophys. Res. Commun. 322, 310-319

96 Calderone, A., Thaik, C. M., Takahashi, N., Chang, D. L. and Colucci, W. S. (1998) Nitric oxide, atrial natriuretic peptide, and cyclic cGMP inhibit the growth-promoting effects of norepinephrine in cardiac myocytes and fibroblasts. J. Clin. Invest. 101, 812-818

97 Laskowski, A., Woodman, O. L., Cao, A. H., Drummond, G. R., Marshall, T., Kaye, D. M. and Ritchie, R. H. (2006) Antioxidant actions contribute to the antihypertrophic effects of atrial natriuretic peptide in neonatal rat cardiomyocytes. Cardiovasc. Res. 72, $112-123$
98 Rubattu, S., Bigatti, G., Evangelista, A., Lanzani, C., Stanzione, R., Zagato, L., Manunta, P., Marchitti, S., Venturelli, V., Bianchi, G. et al. (2006) Association of atrial natriuretic peptide and type-A natriuretic peptide receptor gene polymorphisms with left ventricular mass in human essential hypertension. J. Am. Coll. Cardiol. 48, 499-505

99 Rubattu, S., Sciarretta, S., Ciavarella, G. M., Venturelli, V., De Paolis, P., Tocci, G., De Biase, L., Ferrucci, A. and Volpe, M. (2007) Reduced levels of N-terminal-proatrial natriuretic peptide in hypertensive patients with metabolic syndrome and their relationship with left ventricular mass. J. Hypertens. 25, 833-839

100 Molkentin, J. D. (2003) A friend within the heart: natriuretic peptide receptor signaling. J. Clin. Invest. 111, $1275-1277$

101 Jones, E. C., Devereux, R. B., O’Grady, M. J., Schwartz, J. E., Liu, J. E., Pickering, T. G. and Roman, M. J. (1997) Relation of hemodynamic volume load to arterial and cardiac size. J. Am. Coll. Cardiol. 29, 1303-1310

102 Cuspidi, C., Meani, S., Fusi, V., Severgnini, B., Valerio, C., Catini, E., Sala, C., Sampieri, L., Magrini, F. and Zanchetti, A. (2004) Metabolic syndrome and target organ damage in untreated essential hypertensives. J. Hypertens. 22, 1991-1998

103 Schillaci, G., Pirro, M., Pucci, G., Mannarino, M. R., Gemelli, F., Siepi, D., Vaudo, G. and Mannarino, E. (2006) Different impact of the metabolic syndrome on left ventricular structure and function in hypertensive men and women. Hypertension 47, 881-886

104 Lind, L., Andersson, P. E., Andren, B., Hanni, A. and Lithell, H. O. (1995) Left ventricular hypertrophy in hypertension is associated with the insulin resistance metabolic syndrome. J. Hypertens. 13, 433-438

105 Horio, T., Nishikimi, T., Yoshihara, F., Matsuo, P., Takishita, S. and Kangawa, K. (2000) Inhibitory regulation of hypertrophy by endogenous atrial natriuretic peptide in cultured cardiac myocytes. Hypertension 35, 19-24

106 Sagnella, G. A. (2001) Atrial natriuretic peptide mimetics and vasopeptidase inhibitors. Cardiovasc. Res. 51, 416-428

107 Mitchell, G. F., Izzo, J. L., Lacourcière, Y., Ouellet, J. P., Neutel, J., Qian, C., Kerwin, L. J., Block, A. J. and Pfeffer, M. A. (2002) Omapatrilat reduces pulse pressure and proximal aortic stiffness in patients with systolic hypertension. Results of the Conduit Hemodynamics of Omapatrilat International Research study. Circulation 105, 2955-2961

108 Corti, R., Burnett, J. C., Rouleau, J. L., Ruschitzka, F. and Lüscher, T. F. (2001) Vasopeptidase inhibitors. A new therapeutic concept in cardiovascular disease? Circulation 104, 1856-1862

109 Campbell, D. J. (2001) Vasopeptidase inhibition. A double-edged sword? Hypertension 41, 383-389

110 Woodard, G. E. and Rosado, J. A. (2008) Natriuretic peptides in vascular physiology and pathology. Int. Rev. Cell. Mol. Biol. 268, 59-93 